This syndrome has been recognised only since 1963 and before this confusion with Marfan's syndrome must have occurred, but it is now unlikely in countries with well-developed laboratory services. It is still probable that Marfan's syndrome is genetically heterogeneous. ${ }^{1}-\mathrm{ED}, B M \mathcal{F}$

' Smith, D W, Recognizable Patterns of Human Malformation, $p$ 258. Philadelphia, Saunders, 1970

Penrose, L'S, The Biology of Mental Defect, 4th edn p 145. London, Sidgwick and Jackson, 1972.

Crome, L, and Stern, J, Pathology of Mental Retardation, 1972.

McKusick, V A in Birth Defects: Original Article Series, vol 11, No 6, ed D Bergsma, pp 1-13. Alan R Liss, New York, 1975.

\section{Paracetamol overdosage}

SIR,- The report by $\operatorname{Dr} R \mathrm{D}$ Hughes and others on a controlled trial of cysteamine and dimercaprol after paracetamol overdosage (26 November, p 1395) ends with a plea for a further controlled clinical study with methionine.

In view of the critical need for glutathione to protect the body from the hepatotoxic effects of intermediary metabolites of paracetamol $^{1}$ and the well-documented role of cysteine and acetyl cysteine conjugation in the detoxication mechanism ${ }^{1}: 3$ it would perhaps be more useful to base further control studies on the experience gained so far with $N$-acetyl cysteine, ${ }^{+}$especially as it would appear that cysteamine and $\mathrm{N}$-acetyl cysteine might not be acting by the same mechanism. ${ }^{6}$

Since the time factor after overdosage is so important in determining the outcome of treatment with $\mathrm{SH}$-donor substances; the danger of inducing a biochemical lesion could be minimised or avoided altogether if pharmaceutical preparations of paracetamol incorporated $N$-acetyl cysteine.

W ROBERT JONDORF

Cambridge

Brodie, B, Intra-Science Chemistry Reports, 1974 8, Nos 1-3, p 1

iillette, J R, in Drug Metabolism from Microbe to Man, ed D V Parke and R L Smith, p 147. London, Taylor and Francis, 1977.

Knox, J H, and Jurand, J, fournal of Chromatography, $1977,142,65$

Piperno,

Prescott, L F, et al, Lancet, 1977, 2, 432

Prescott, L F, et al,
Lancet, 1975, 2, 1189 .

British Medical fournal, 1977, 2, 481.

SIR,-We read with interest the report by Dr R D Hughes and others (26 November, $p$ 1395) of a controlled trial of cysteamine and dimercaprol following paracetamol overdose but noted that it suggests that cysteamine is inconvenient to use.

In their report the authors mention that the cysteamine infusions used in the trial were freshly prepared and then filtered through a Millipore filter. One assumes that this method of preparation was used because of the initial problems with cysteamine stability. ${ }^{12}$

It has been demonstrated that cysteamine hydrochloride is stable to autoclaving and storage. ${ }^{34}$ In order to make the injection easier to use we have, since 1976 , produced the solution as an initial dose of $2 \mathrm{~g}$ in $120 \mathrm{ml}$ isotonic solution in a $125-\mathrm{ml}$ transfusion bottle, with subsequent doses in 10-ml ampoules. This provides a convenient dosage form for ease of use which can easily be produced by any hospital sterile manufacturing unit.

We cannot therefore understand the need for freshly prepared solutions when such a proved and convenient method of use is available.

$M$ J TARR

Pharmacy Department, University Hospital of Wales,

Prescott, L F, et al, Lancet, 1974, 1, 588

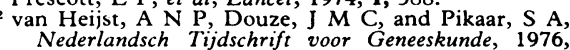
120, 1151

Brouwers, J R B, and Vermeij, P, Pharmaceutisch W'eekblad, 1976, 111, 204.
Prior, F G R, Lancet, 1977, 1, 315.

\section{Confidentiality and life insurance}

SIR,-I should be grateful if you would allow me to comment on the letter (10 December, $p$ 1544) from $\mathrm{Dr} T M$ Pickard regarding confidentiality and life assurance. His conclusions, reflected in the last paragraph of his letter, demonstrate the misunderstanding of life assurance and the work of the underwriter which is all too prevalent-not only in the medical profession. Perhaps I can clarify the situation.

The principal objectives of a life assurance office are to give cover and to pay claims. The protection of life assurance for family commitments, etc, is much sought after, as is evidenced by the considerable total of premiums paid to life offices during each year. The cost of this protection is calculated from the mortality statistics of assured lives, and if offices allowed proposers to have cover at the normal rates of premium when their mortality was likely to be substantially greater than the standard, then the office would make a loss. It is the underwriter's job to assess those who propose for life assurance and assess the extra mortality of any who do not fit into the standard of the life office. Each office has its own standard so the number not accepted at the ordinary rate of premium will vary, but is likely to be between $5 \%$ and $10 \%$ of the total.

Dr Pickard has drawn attention to the fact that many people who fill in forms do not read them, nor do they understand their implications. I do not think anyone would disagree with him here. Unfortunately, this fault is not confined to the completion of proposals for life assurance, nor is it confined to those outside the medical profession. However, Dr Pickard's objection is to the position of the underwriter as it affects his relationship with his patien and casts the life assurance office as the villain. An underwriter is conscious of the very special doctor-patient relationship and does all he can to preserve it. One of the main difficulties arises when a doctor makes clinical judgment not to tell his patient the full implication of his troubles, perhaps placing the underwriter in the position of having to decline the proposal for no apparent reason. The natural reaction is for the patient to ask his doctor what is wrong with him. The only help an underwriter can give is to pay for an unnecessary independent examination in the hope that this will offer some protection to the doctor. Unfortunately Dr Pickard has illustrated his comments by referring to menta disturbances. This is probably the most difficult disorder for any doctor to combat and it is no less difficult for the underwriter. It is made more difficult for the underwriter because of the loose terminology used. Words like "depressed" and "anxious" have differen meanings to the layman and the clinician.
If an underwriter is faced with a proposal in which he is told "I saw my doctor for depression" what is he to believe ? It could mean anything between "I felt run down" or "I didn't feel up to it" to the proposer being a manic-depressive. The treatment could be anything between $1 \%$ tranquillisers plus $99 \%$ reassurance and regular treatment with lithium carbonate. The underwriter cannot possibly make a balanced judgment without help from the medical adviser and any report requested is for the benefit of the patient and certainly not to "be used in evidence against him".

It is understandable that doctors may feel their patients are unaware of the implications of giving authority to the doctor to furnish reports. It is a not uncommon practice in such circumstances for the doctor to request separate written authority from the patient. This is of course expensive and time-wasting, but if the doctor feels the circumstances warrant his patient being more forcibly reminded of the disclosure he is authorising, then it is a very worthwhile precaution. A photocopy of the permission already granted, as suggested by Dr A J Caro (7 January, p 50), might, however, serve this purpose.

The comments I have made do not apply solely to mental disturbances, but to the whole scope of medicine. I hope they have at least put the underwriter's point of view that nothing he does is against the patient but entirely for his benefit. If it were not this way round we, of course, would soon be out of business.

V H KENDALL Underwriter,
National Provident Institution

Tunbridge Wells

\section{Dietary cholesterol and atherosclerosis}

SIR,-It is good that Professor John Yudkin ( 3 December, $p$ 1477) should remind us of the pioneering work of Anitschkow, who established the principle of what he called "dietary atherosclerosis." Anitschkow's meticulous work describing how he tracked down the culprit cholesterol in egg yolk and later in brain is still fascinating to read. Time marches on and his findings have been confirmed by many workers in many different species-in fact in all in which the plasma cholesterol concentration is raised, ${ }^{1}$ including our nearest relatives, the non-human primates. The stronger the stimulus, the more cellular is the response, but with a lesser stimulus continued for a longer time progressively, even in rabbits, the changes more closely resemble those occurring in man. Wissler and his colleagues in Chicago, ${ }^{12}$ by feeding actual Western diets to rhesus monkeys, which are closely similar to man in their anatomical, physiological, and biochemical features and not spontaneously prone to atherosclerosis, have produced severe arterial changes similar to those seen in humans.

Anitschkow noted, as must have most physicians in their patients, that hypercholesterolaemia (by conventional standards) is not always present. This is not surprising because other factors, including in particular the permeability of the arterial wall and even mild elevation of blood pressure, are also important. Many pathologists, including in particular Oxborn, ${ }^{3}$ have shown that pathological changes in the coronary arteries are frequently present in children and preatheromatous changes even in infancy. Ex- 
perimentally it is well established that once the endothelial barrier is breeched the stage is set for atherosclerosis and even a mild rise in plasma cholesterol concentration above 5.5 $\mathrm{mmol} / \mathrm{l}(220 \mathrm{mg} / 100 \mathrm{ml})$ is sufficient to induce atherosclerotic change. However, changes may develop before there is any detectable rise in blood lipids. ${ }^{4}$

It is hardly to be expected that dietary cholesterol as calculated from tables and on a single occasion would be representative of the usual amount consumed from day to day and over the many years of developing atherosclerosis. However, it is known that dietary cholesterol contributes about one-quarter to one-third to plasma cholesterol, ${ }^{5}$ which is a very substantial amount since the body synthesises all its requirements. Plasma concentrations are also greatly influenced by the amount and composition of fat in the diet.

Professor Yudkin makes no reference to these important aspects, an appreciation of which puts the situation into better prospective.

University of Edinburgh

RICHARD TURNER

Wissler, R W, and Vesselinovitch, D, Advances in Lipid Research, 1968, 6, 181.

Wissler, R W, and Vesselinovitch, D, Diet and Atherosclerosis, ed C Sirtori, G Ricci, and S Gorin p 66. New York, Plenum Publishing Co, 1976. Osborn, G R, Incubation Period of Coronary Thro bosis, pp 177-190. London, Butterworths, 1963.

Cox, G E, et al, Archives of Pathology, 1963, 76, 166 aplan, J A, Cox, GE, and

\section{Antidepressants-yes or no?}

SIR,-Drs R J Kerry and J E Orme (10 December, $p$ 1538) are right to remind us of the value of comparing drug- and placebo-responders. They suggest that "an important proportion" of the women on placebo in my trial of viloxazine (19 November, $p$ 1327) might be under 40 years of age. There were, in fact, three women under 40 on placebo and four on viloxazine. Of the three on placebo, two were "very much improved" and one showed "no change" following treatment. Of those who received viloxazine, one was "much improved," one showed "no change," and two were "slightly worse."

Equal numbers of patients received viloxazine and placebo, but all of the five "dropouts" were on viloxazine. The accompanying table shows the breakdown data of the global assessments of change in condition according to sex and age for those who completed the study. It can be seen that more women (7) than men (1) improved on placebo, but more patients over 40 years of age (6) than under 40 (2) also improved on placebo.

Drs Kerry and Orme provide further support for the inclusion of placebo controls in trials of antidepressants. We hesitate to use these but should find some assurance from the

Response to treatment according to sex and age

\begin{tabular}{|c|c|c|c|c|c|c|c|c|c|c|}
\hline \multicolumn{3}{|c|}{ Change in condition } & \multicolumn{2}{|c|}{ Viloxazine } & \multicolumn{2}{|c|}{ Placebo } & \multicolumn{2}{|c|}{ Viloxazine } & \multicolumn{2}{|c|}{ Placebo } \\
\hline $\begin{array}{l}\text { Very much improved } \\
\text { Much improved } \\
\text { Moderately improved } \\
\text { Slightly improved } \\
\text { No change } \\
\text { Slightly worse } \\
\text { Much worse }\end{array}$ & $\begin{array}{l}. . \\
\ldots \\
\cdots \\
\cdots \\
\cdots \\
\cdots\end{array}$ & $\begin{array}{l}\ldots \\
\cdots \\
\cdots \\
\cdots \\
\cdots\end{array}$ & $\begin{array}{l}1 \\
1 \\
2\end{array}$ & $\begin{array}{l}1 \\
3 \\
1 \\
2 \\
1\end{array}$ & 1 & $\begin{array}{l}3 \\
1 \\
1 \\
2 \\
2 \\
1\end{array}$ & 1 & 3 & 2 & $\begin{array}{l}2 \\
1 \\
1 \\
2 \\
3 \\
1 \\
1\end{array}$ \\
\hline \multicolumn{3}{|c|}{ Total } & 4 & 8 & 7 & 10 & 6 & 6 & 6 & 11 \\
\hline
\end{tabular}

fact that placebos, although inert pharmacologically, are active therapeutically. In 15 studies involving 1082 patients with a wide variety of organic and psychiatric disorders placebos had an average significant effectiveness of $35.2 \%$ and were most effective when stress was greatest. ${ }^{1}$ In the Medical Research Council's trial' ${ }^{2}$ of the treatment of depressive illness about a third of the patients receiving placebo "wholly, or almost wholly, lost their symptoms" within the first four weeks.

Those opposed to the use of placebos should be reminded that many physicians-perhaps themselves included-already practice placebo therapy by: (1) prescribing drugs of unproved pharmacological value; (2) prescribing active drugs in conditions unresponsive to their pharmacological actions; or (3) prescribing active drugs in ineffective dosages. Ethical arguments against the use of placebo controls in depression can be countered by the statement that it is unethical not to use them. Without them there is a risk that new drugs that are no more effective than placebos will enter clinical practice on a wide scale and carry the risk of serious unwanted effects or interactions with other drugs or chemicals.

Finally, a word of warning to those most squeamish about the use of placebos: beware of their side effects. True, most of these are mild, but they can be quite severe."

\section{J GUY EDWARDS}

Knowle Hospital

1 Beecher, H K, Fournal of the American Medical Association, 1955, 159, 1602

Medical Research Council, British Medical fournal, $1965,1,881$. Wolf, S, and Pinsky, R H, fournal of the American

\section{Positioning of nasogastric tubes}

SIR,-Nasogastric tubes are used for aspiration of gastric contents or for feeding. When the patient is conscious and co-operative the tube may be passed by nursing staff and positioning confirmed radiologically or by the recovery of swallowed marker fluid. When the patient is unconscious positioning may be confirmed by aspiration of gastric contents. However, such material may be aspirated from the lower oesophagus after regurgitation through an incompetent cardiac sphincter, and metoclopramide can so empty a stomach that very little contents remain to be withdrawn. Such patients cannot swallow, and reasonable quantities of fluid may be injected and recovered from a tube coiled up within the oesophagus.

I inject $5 \mathrm{ml}$ of water and $5 \mathrm{ml}$ of air together down the tube while auscultating the left subcostal area. If the nasogastric tube is lying free within the stomach sounds can be heard on injection and aspiration, but if the tube is

lying within the cardiac sphincter or is kinked within the stomach sounds will be heard only on injection. If barbotage produces no sounds the tube is coiled within the oesophagus and a further attempt at positioning must be made. Both water and air must be used together since either alone may enter and leave the stomach silently.

This test may also be used to confirm the position and patency of a tube should gastric suction suddenly produce no contents.

E N S FRY

Department of Anaesthesia,

Nepartment of Anaesthesia,

Stockton-on-Tees,

Cleveland

\section{Smoking and asthma}

SIR,-It has become apparent that type 3 allergy is commoner in non-smokers and it is thought that the effect of smoking may produce a protective lining of mucus so that the allergen does not reach the bronchial mucosa. ${ }^{1}$ I have seen two patients this month who developed type 1 allergy as soon as they gave up smoking, in one case to cats and the other to the house dust mite. Should we therefore encourage our asthmatic patients to smoke? Many chronic bronchitic patients find that the first cigarette of the day clears their lungs and gets rid of all their sputum and they are free for the next few hours. It may be that the old herbal cigarettes for asthma which contained stramonium had this beneficial effect.

F E DE W CAYLEY

Brighton Chest Clinic,
Brighton, Sussex

Warren, C P W, Thorax, 1977, 32, 567.

\section{Return to normal of Argyll Robertson pupils after treatment}

SIR,- The short report by Dr F M LaniganO'Keefe (5 November, $p$ 1191) raises points of interest concerning the diagnosis of pupillary abnormalities.

Loss of the light reaction with retained accommodation response remains the principal sign of Argyll Robertson pupil. However, a wide range of pupil disturbances can exhibit an identical dissociation-for example, myotonic pupils, Parinaud's syndrome, partial internal ophthalmoplegia, and drugs. Argyll Robertson pupil is the classical cause of this dissociation but is now one of its rarer causes. The identification of the mimics of Argyll Robertson pupil demands careful neuroophthalmic examination including pharmacological responses.

The original cases reported by Argyll Robertson ${ }^{1}$ exhibited bilateral light-near dissociation accompanied by insignificant visual impairment, poor response to mydriatics, and constricted, irregular pupils. The classical Argyll Robertson pupil is invariably attributable to neurosyphilis and hence the importance of its correct identification.

Neuro-ophthalmology Department,

R CoOLING

National Hospital,

Queen Square

1 Argyll Robertson, D M C L, Edinburgh Medical fournal, 1869, 15, 487 . 